\title{
Structure and magnetic properties of vanadium-sodium silicate glasses
}

\author{
A. Mekki ${ }^{a, *}$, G.D. Khattak ${ }^{\text {a }}$, D. Holland ${ }^{b}$, M. Chinkhota ${ }^{\text {c }}$, L.E. Wenger ${ }^{\text {c }}$ \\ a Department of Physics, King Fahd University of Petroleum and Minerals, Dhahran 31261, Saudi Arabia \\ ${ }^{\mathrm{b}}$ Department of Physics, University of Warwick, Coventry CV4 7AL, UK \\ c Department of Physics and Astronomy, Wayne State University, Detroit, MI 48201, USA
}

Received 4 April 2002

\begin{abstract}
Vanadium-sodium silicate glasses with the chemical composition $\left[\left(\mathrm{V}_{2} \mathrm{O}_{5}\right)_{x}\left(\mathrm{Na}_{2} \mathrm{O}\right)_{0.30}\left(\mathrm{SiO}_{2}\right)_{0.70-x}\right](0.0 \leqslant x \leqslant 0.10)$ have been studied by X-ray photoelectron spectroscopy (XPS) and magnetization measurements. The core-level binding energies of $\mathrm{O} 1 \mathrm{~s}, \mathrm{~V} 2 \mathrm{p}$ and $\mathrm{Si} 2 \mathrm{p}$ in these glasses have been measured for surfaces produced by in vacuo fracture. The peak position and width of the $\mathrm{V} 2 \mathrm{p}_{3 / 2}$ peak are independent of the $\mathrm{V}_{2} \mathrm{O}_{5}$ content while the $\mathrm{O}$ 1s core-level spectra show significant composition-dependent changes. Two distinct peaks are resolvable arising from the bridging oxygen and non-bridging oxygen (NBO) atoms in the silicate glasses. The fraction of NBO, determined from these spectra is found to increase with increasing $\mathrm{V}_{2} \mathrm{O}_{5}$ content in the glass and are consistent with the formation of predominantly alkali metavanadate species. The magnetic susceptibility data of these glasses indicate a large, temperature-independent diamagnetic contribution arising from the glass matrix as well as small paramagnetic contribution from the $\mathrm{V}^{4+}$ ions. The $\mathrm{V}^{4+}$ content deduced from the magnetization results $(\sim 2 \%)$ is below the detection limit of XPS analysis.
\end{abstract}

(c) 2002 Elsevier Science B.V. All rights reserved.

\section{Introduction}

In recent years there have been several examples where X-ray photoelectron spectroscopy (XPS) has been used to study the electronic structure and spectral characteristics of transition metal oxides $[1,2]$. Specifically, XPS has been used to measure the chemical shifts associated with core level photoemission spectra when non-equivalent atoms of the same element in a solid give rise to core level

\footnotetext{
${ }^{*}$ Corresponding author. Tel.: +966-3 860 4292; fax: +966-3 8602293.

E-mail address: akmekki@kfupm.edu.sa (A. Mekki).
}

peaks with measurably different binding energies. XPS has also proved to be a useful tool for investigating the structure of oxide glasses [3]. For example, XPS is able to differentiate between bridging oxygen (BO) and non-bridging oxygen atoms (NBO) in the glass structure for binary glasses [4-6] as well as more complex systems [7-10]. Satellite structures associated with the $2 \mathrm{p}$ core level peaks of transition metals which have been introduced into oxide glasses have been observed and used qualitatively to identify the oxidation state of the TM ion [11]. More recently, XPS has successfully determined the content of different oxidation states of transition metals in oxide glasses, such as iron, 
vanadium and copper in sodium silicate, phosphate and borate glasses [12-18].

Studies of oxide glasses containing transitionmetal (TM) oxides continue to be of technological interest because of the semiconducting properties that arise from electron hopping between two TM ions having different valence states in these glasses [19-22]. Structural and electronic properties of these glasses as well as their optical, magnetic and mechanical properties depend on the relative proportions of the different valence states of the TM ions present [23-25]. In order to account for the effect of valence state on the structure and properties of these glasses, it is important to control and measure the proportions of the TM ions in the different valence states in these oxide glasses. In previous studies [26-29], electron paramagnetic resonance (EPR) has been found to be a useful technique for examining the states of dissimilar TM ions in these glasses as well as the interactions between unlike magnetic ions in disordered solids.

In the present work, conclusions on the valence state of $\mathrm{V}$ ions in vanadium sodium silicate glasses will be presented based on XPS spectra in combination with magnetization measurement data. Generally, when vanadium is introduced in large quantities in oxide glasses, it acts as a glass former; however, very little work has been done on glass systems containing small quantities of $\mathrm{V}_{2} \mathrm{O}_{5}$ $(<10 \%)$. The objective of the present work is to measure the NBO content, to identify the different oxidation states of vanadium ions and to identify the nature of the magnetic interaction in these lowconcentration vanadium sodium silicate glasses.

\section{Experimental procedure}

\subsection{Glass preparation}

The glass compositions studied have the general formula $\left[\left(\mathrm{V}_{2} \mathrm{O}_{5}\right)_{x}\left(\mathrm{Na}_{2} \mathrm{O}\right)_{0.30}\left(\mathrm{SiO}_{2}\right)_{0.70-x}\right]$ with nominal $x=0,0.025,0.050,0.075$ and 0.100 values. Analytical grade powders of $\mathrm{V}_{2} \mathrm{O}_{5}, \mathrm{Na}_{2} \mathrm{CO}_{3}$ (for $\mathrm{Na}_{2} \mathrm{O}$ ) and $\mathrm{SiO}_{2}$ in the required stoichiometric ratios were melted in platinum crucibles at temperatures ranging from 1300 to $1400{ }^{\circ} \mathrm{C}$, depending on the composition. The melts were cast into preshaped graphite coated steel moulds yielding glass rod specimens with dimensions of $6 \times 6 \times 30$ $\mathrm{mm}^{3}$. The bars were annealed at a temperature 50 ${ }^{\circ} \mathrm{C}$ below their glass transition temperature $\left(T_{\mathrm{g}}\right.$ determined from differential thermal analysis DTA) for $2 \mathrm{~h}$ and then cooled to room temperature at a rate of $30{ }^{\circ} \mathrm{C}$ per hour. X-ray powder diffraction patterns were taken for the five compositions to check for the presence of crystalline phases and none were detected. After preparation, the samples were stored in a desiccator in order to minimize water absorption. Chemical compositions were determined by inductively coupled plasma (ICP) emission spectroscopy and the results of the analysis are shown in Table 1. The small differences between the batch and the analyzed glass compositions indicate that very little material evaporated during the melting process.

\subsection{X-ray photoelectron spectroscopy}

The XPS spectra of C 1s, V 2p, O 1s, Si 2p and $\mathrm{Na} 1 \mathrm{~s}$ core levels were recorded with a VG Scientific ESCALAB MK II system described elsewhere [30] with a base pressure $<5 \times 10^{-10} \mathrm{mbar}$ in both the preparation and spectrometer vessels. The XPS spectra were obtained using non-monochromatic AlK $\alpha$ radiation operating at $130 \mathrm{~W}$. The analyzer was operated in a constant resolution mode with a pass energy of $10 \mathrm{eV}$ and a reduced exit slit for high resolution spectroscopy (the analyzer energy resolution is $0.9 \mathrm{eV}$ ), while a pass energy of $50 \mathrm{eV}$ was used for routine survey scans. The energy scale of the spectrometer was calibrated using the following photoelectron lines: $\mathrm{Cu} 2 \mathrm{p}_{3 / 2}=932.67 \mathrm{eV}$ and $\mathrm{Au}$ $4 \mathrm{f}_{7 / 2}=83.98 \mathrm{eV}$. Binding energies are subse-

Table 1

Nominal and ICP analyzed compositions of the vanadiumsodium silicate glasses

\begin{tabular}{llllllll}
\hline$x$ & \multicolumn{2}{l}{ Nominal } & & \multicolumn{3}{l}{ Analyzed } \\
\cline { 2 - 3 } \cline { 7 - 8 } & $\mathrm{Na}_{2} \mathrm{O}$ & $\mathrm{SiO}_{2}$ & $\mathrm{~V}_{2} \mathrm{O}_{5}$ & & $\mathrm{Na}_{2} \mathrm{O}$ & $\mathrm{SiO}_{2}$ & $\mathrm{~V}_{2} \mathrm{O}_{5}$ \\
\hline 0.000 & 0.300 & 0.700 & 0.000 & & 0.310 & 0.690 & 0.000 \\
0.025 & 0.300 & 0.675 & 0.025 & & 0.291 & 0.683 & 0.026 \\
0.050 & 0.300 & 0.650 & 0.050 & & 0.284 & 0.668 & 0.048 \\
0.075 & 0.300 & 0.625 & 0.075 & & 0.293 & 0.632 & 0.075 \\
0.100 & 0.300 & 0.600 & 0.100 & & 0.292 & 0.610 & 0.098 \\
\hline
\end{tabular}

The relative uncertainty in the ICP results is $\pm 5 \%$. 
quently referenced to the carbon $1 \mathrm{~s}$ line at $284.6 \mathrm{eV}$ in other XPS spectra, resulting in a $\pm 0.2 \mathrm{eV}$ uncertainty in the binding energy determinations. The C 1s peak in the XPS spectra arises from hydrocarbon contaminants in the vacuum and is generally accepted to be independent of the chemical state of the sample under investigation. Each sample was fractured in the preparation chamber under ultra-high vacuum (UHV) conditions prior to XPS analysis in order to (i) reduce the signal from surface contamination due to oxygen and carbon from the atmosphere and (ii) minimize any differences between the surface investigated by XPS and the actual bulk state of the glass.

All high-resolution spectra have been shifted to correct for the charging effects associated with insulating samples. Information concerning oxygen bonding and the valence state of vanadium were obtained by resolving the $\mathrm{O} 1 \mathrm{~s}$ spectrum and the $\mathrm{V}$ $2 p$ spectrum into the weighted sums of two Gaussian-Lorentzian peaks representing bridging and $\mathrm{NBO}$ atoms and $\mathrm{V}^{4+}$ and $\mathrm{V}^{5+}$, respectively. The reproducibility of these quantitative spectral decompositions for both $\mathrm{V} 2 \mathrm{p}$ and $\mathrm{O} 1 \mathrm{~s}$ spectra was checked by repeating the analysis on spectra taken from other surfaces of the glass samples with the overall uncertainty estimated to be to $\pm 10 \%$ and $\pm 5 \%$, respectively.

\subsection{Magnetization measurements}

The temperature-dependent dc magnetic susceptibility was measured using a Quantum Design SQUID magnetometer (model MPMS-5S) in a magnetic field of 5000 Oe over a temperature range of 5-300 K. The susceptibility of the sample holder is negligible below $100 \mathrm{~K}$ for all samples and constitutes less than a $2 \%$ correction at the highest temperature for all samples. The overall accuracy of the magnetic measurements is estimated to be approximately $3 \%$ due to the uncertainty of the magnetometer calibration.

\section{Results}

XPS survey scans for two glass compositions obtained on newly fractured surfaces are shown in
Fig. 1. The XPS and Auger core level peaks from the constituent elements in the glass are easily identifiable as well as the presence of a very weak $\mathrm{C}$ 1s peak. High resolution scans in the vicinity of the $\mathrm{C} 1 \mathrm{~s}$ peak show a single narrow and symmetric peak at a binding energy of $284.6 \mathrm{eV}$, which is usually associated with carbon contamination from the vacuum chamber. In comparison, the $\mathrm{C}$ 1s peak associated with $\mathrm{Na}_{2} \mathrm{CO}_{3}$ has a higher binding energy of $289.3 \mathrm{eV}$ [31]. The absence of this higher binding energy transition in all $\mathrm{C} 1 \mathrm{~s}$ spectra for these glasses indicates that there are no bonded carbons in our glass samples and that all $\mathrm{Na}_{2} \mathrm{CO}_{3}$ has decomposed into $\mathrm{Na}_{2} \mathrm{O}$ with the $\mathrm{CO}_{2}$ evaporating from the melt.

Fig. 2 shows the high-resolution V 2p spinorbit doublet spectra for the vanadium-containing glass samples. The peak intensity increases with increasing $\mathrm{V}_{2} \mathrm{O}_{5}$ content in the glasses, while the peak position and width of the $\mathrm{V} 2 \mathrm{p}_{3 / 2}$ peak at $\sim 517 \mathrm{eV}$ do not vary with composition.

The $\mathrm{O} 1 \mathrm{~s}$ core level high-resolution spectra for the $0.026 \leqslant x \leqslant 0.098$ glasses displayed in Fig. 3 show three distinct peaks. The highest binding energy peak, located at $535 \mathrm{eV}$, corresponds to the sodium $\mathrm{KL}_{1} \mathrm{~L}_{23}$ Auger transition and the intensity of this peak does not vary with glass composition since the $\mathrm{Na}_{2} \mathrm{O}$ content is essentially constant. The

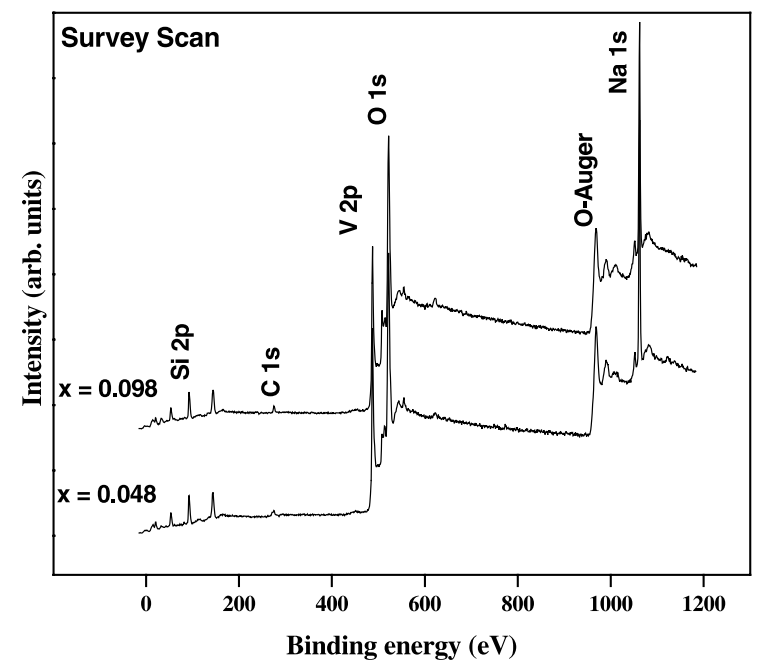

Fig. 1. XPS survey scans of two fractured vanadium sodium silicate glasses. 


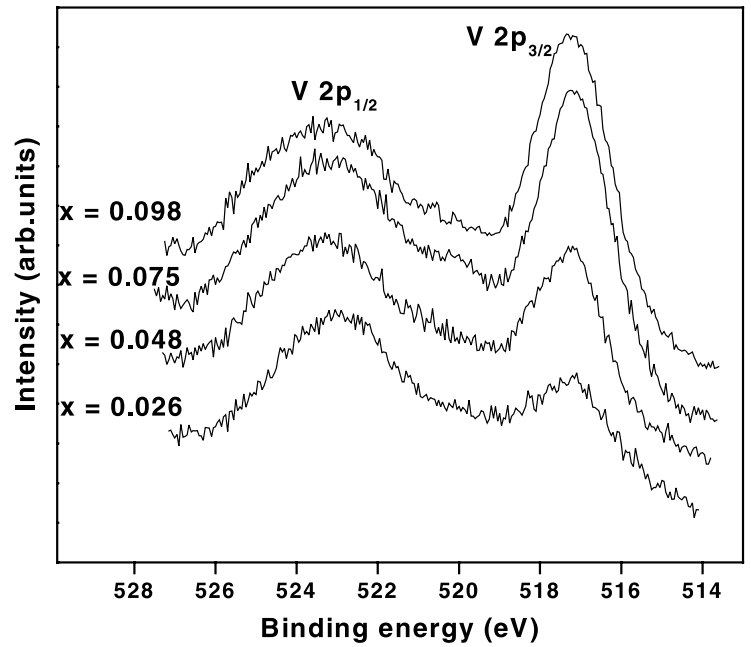

Fig. 2. High-resolution core level spectra of the V $2 p$ transition for fractured glass samples with varying $\mathrm{V}_{2} \mathrm{O}_{5}$ content.

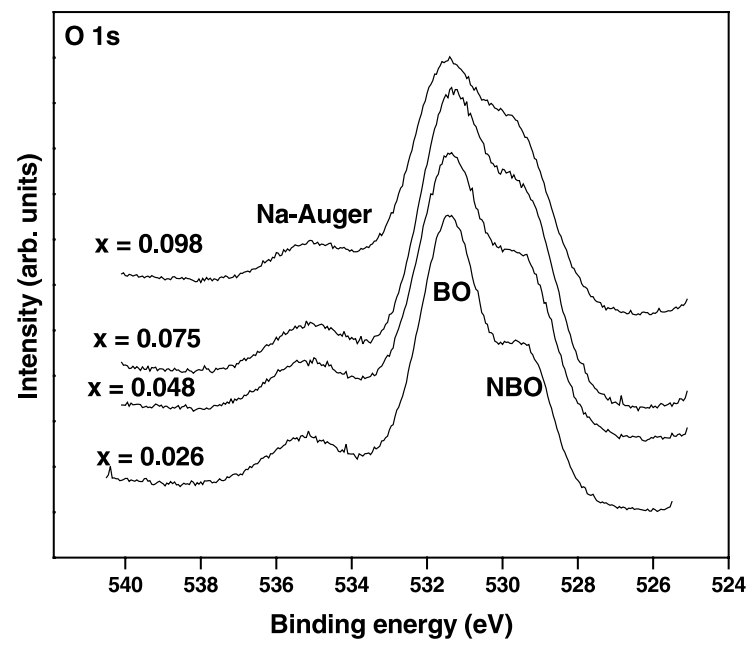

Fig. 3. High-resolution $\mathrm{O} 1 \mathrm{~s}$ core level spectra for the $\mathrm{V}_{2} \mathrm{O}_{5}$ sodium silicate glass samples.

other two peaks, one at $\sim 530 \mathrm{eV}$ corresponding to a contribution from NBO atoms and the other at $\sim 532 \mathrm{eV}$ attributed to $\mathrm{BO}$ atoms, do have a compositional dependence, with the relative intensity of the $530 \mathrm{eV}$ peak increasing as more $\mathrm{V}_{2} \mathrm{O}_{5}$ is added to the $0.30 \mathrm{Na}_{2} \mathrm{O}-0.70 \mathrm{SiO}_{2}$ base glass system.

The magnetic susceptibility results for these glasses are displayed in Fig. 4 as plots of the

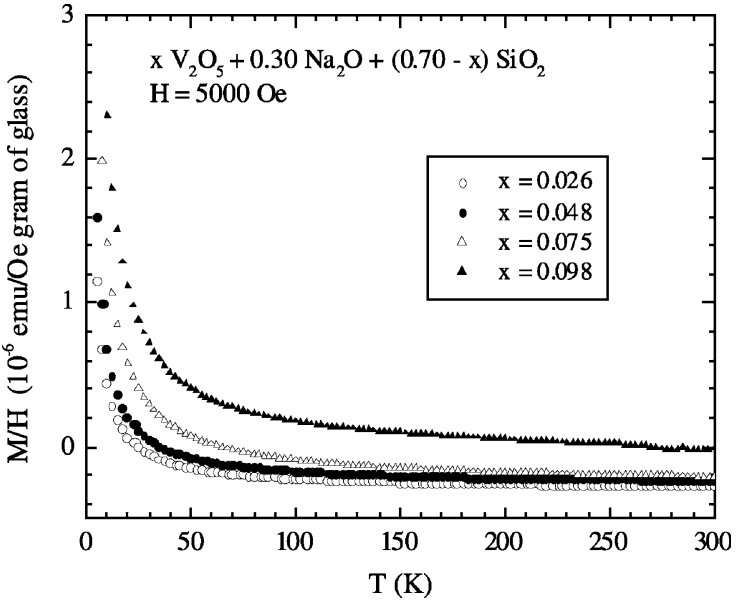

Fig. 4. The magnetic susceptibility $M / H$ as a function temperature $T$ for the $\left(\mathrm{V}_{2} \mathrm{O}_{5}\right)_{x}\left(\mathrm{Na}_{2} \mathrm{O}\right)_{0.30}\left(\mathrm{SiO}_{2}\right)_{0.70-x}$ glass samples.

magnetic susceptibility, $M / H$, as a function of the temperature $T$. The susceptibility data do not appear to follow a Curie-Weiss behavior $(M / H=$ $C /(T-\theta))$ as the susceptibility becomes negative and nearly temperature independent at temperatures above $100 \mathrm{~K}$. After attempting several other fitting possibilities, it was found that the data for each sample could be satisfactorily fitted to a negative temperature-independent constant plus a simple Curie temperature-dependent contribution. The temperature-independent constants are determined from a high-temperature extrapolation of $M / H$-vs- $1 / T$ plots for temperatures above 200 $\mathrm{K}$ (see Fig. 5). After subtracting these temperature-independent constants from the measured susceptibility data, the resulting $M^{*} / H(=M / H-$ $\left.(M / H)_{\text {constant }}\right)$ data follow a simple Curie behavior $(M / H=C / T)$ as demonstrated in Fig. 6. The resulting parameters- $(M / H)_{\text {constant }}$ and the Curie constant $C_{\text {expt }}$ obtained from this fitting procedure are listed in Table 2 for all samples. Note that the temperature-independent term, $(M / H)_{\text {constant }}$, is of the same order as the Curie contribution at room temperature. Moreover, it was found that fitting the $M^{*} / H\left(=M / H-(M / H)_{\text {constant }}\right)$ data to a Curie-Weiss behavior with the inclusion of the non-zero paramagnetic Curie temperature $\theta$ did not significantly improve the fit over the simple Curie behavior $(\theta=0)$. 


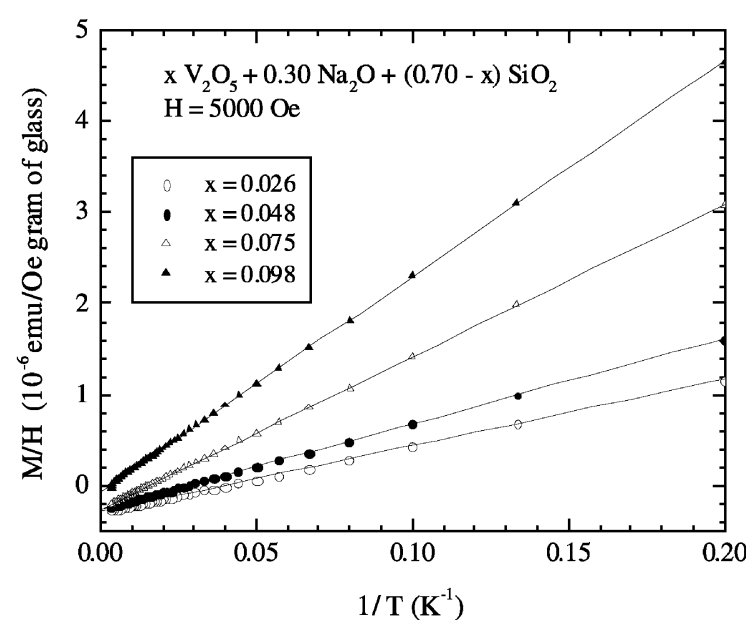

Fig. 5. The magnetic susceptibility $M / H$ as a function of the inverse temperature $1 / T$ for $\left(\mathrm{V}_{2} \mathrm{O}_{5}\right)_{x}\left(\mathrm{Na}_{2} \mathrm{O}\right)_{0.30}\left(\mathrm{SiO}_{2}\right)_{0.70-x}$ glass samples. The solid lines are the high-temperature extrapolations for determining $(M / H)_{\text {constant }}$.

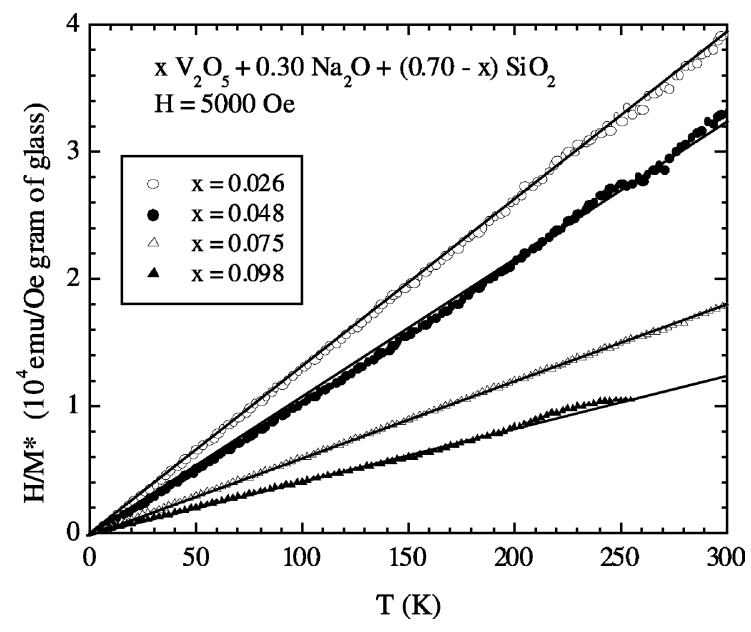

Fig. 6. The inverse of the magnetic susceptibility $H / M^{*}$ as a function of the temperature for $\left(\mathrm{V}_{2} \mathrm{O}_{5}\right)_{x}\left(\mathrm{Na}_{2} \mathrm{O}\right)_{0.30}\left(\mathrm{SiO}_{2}\right)_{0.70-x}$ glass samples. The solid lines represent fits to a Curie temperature-dependent behavior.

Table 2

Magnetic susceptibility results and determinations of $\mathrm{V}^{4+} / \mathrm{V}_{\text {total }}$ for vanadium-sodium-silicate glasses

\begin{tabular}{llll}
\hline$x$ & $\begin{array}{l}(M / H)_{\text {constant }} \\
(\mathrm{emu} / \text { Oe g })\end{array}$ & $\begin{array}{l}C_{\text {expt }} \\
(\mathrm{emu} \mathrm{K} / \text { Oe g })\end{array}$ & $\begin{array}{l}\mathrm{V}^{4+} / \mathrm{V}_{\text {total }} \\
(\%)\end{array}$ \\
\hline 0.026 & $-2.90 \times 10^{-7}$ & $7.28 \times 10^{-6}$ & 2.5 \\
0.048 & $-2.60 \times 10^{-7}$ & $9.39 \times 10^{-6}$ & 1.7 \\
0.075 & $-2.64 \times 10^{-7}$ & $16.76 \times 10^{-6}$ & 2.1 \\
0.098 & $-0.693 \times 10^{-7}$ & $23.74 \times 10^{-6}$ & 2.4 \\
\hline
\end{tabular}

\section{Discussion}

The observation that the peak position and the width of the $\mathrm{V} 2 \mathrm{p}_{3 / 2}$ peak do not change with the $\mathrm{V}_{2} \mathrm{O}_{5}$ content in these glasses (Table 3) suggests that vanadium probably exists in only one oxidation state. It is known [32,33] that the core level spectrum of $\mathrm{V}^{4+}$ has a $2 \mathrm{p}_{3 / 2}$ binding of $515.95 \mathrm{eV}$ while the core level spectrum of $\mathrm{V}^{5+}$ has a $2 \mathrm{p}_{3 / 2}$ binding energy of $517.2 \mathrm{eV}$ for vanadium oxide surfaces. Thus deconvoluting the $\mathrm{V} 2 \mathrm{p}_{3 / 2}$ core level peak into two contributions, one from the $\mathrm{V}^{4+}$ ions at a binding energy of $515.95 \mathrm{eV}$ and the other due to $\mathrm{V}^{5+}$ ions at a binding energy of $517.2 \mathrm{eV}$, should permit a more quantitative estimate of the relative $\mathrm{V}$ concentration for these two oxidation states of vanadium. The sum of two weighted GaussianLorentzian peaks centered at $\approx 515.9$ and $517.2 \mathrm{eV}$ is then fitted to the experimental data. It is clear from Fig. 7(a) and (b) that the V 2 $\mathrm{p}_{3 / 2}$ high-resolution spectra for the $x=0.098$ and 0.048 glass samples can be satisfactorily fitted with a single Gaussian-Lorentzian peak centered at $517.2 \mathrm{eV}$ which indicates no $\mathrm{V}^{4+}$ ions are present beyond the $5 \%$ detection limit of the technique. Similar quantitative fits are found for the other two glass compositions.

The observation that the relative intensities of the double-peak structure in the $\mathrm{O}$ 1s core level spectra (see Fig. 3) change with V content indicates that the local structure surrounding the $\mathrm{O}$ atoms changes with the addition of vanadium to these sodium silicate glasses. For sodium silicate glasses, it is known that the $\mathrm{SiO}_{4}$ tetrahedral network is broken up as the introduction of $\mathrm{Na}_{2} \mathrm{O}$ causes some of the oxygen atoms to be bonded to only

Table 3

Parameters derived from analysis of the V 2 p core level spectra for the V-doped sodium silicate glasses

\begin{tabular}{llll}
\hline$x$ & $\begin{array}{l}\text { V 2 } p_{3 / 2} \text { binding } \\
\text { energy }(\mathrm{eV})\end{array}$ & $\begin{array}{l}\mathrm{V} \mathrm{2} \mathrm{p}_{3 / 2} \\
\text { FWHM }(\mathrm{eV})\end{array}$ & $\begin{array}{l}{\left[\mathrm{V}^{5+}\right] / \mathrm{V}_{\text {total }}} \\
(\%)\end{array}$ \\
\hline 0.026 & 517.11 & 1.87 & 100 \\
0.048 & 517.21 & 1.85 & 100 \\
0.075 & 517.19 & 1.84 & 100 \\
0.098 & 517.17 & 1.90 & 100 \\
\hline
\end{tabular}

The experimental uncertainty in the energy measurements is estimated to be $\pm 0.2 \mathrm{eV}$. 

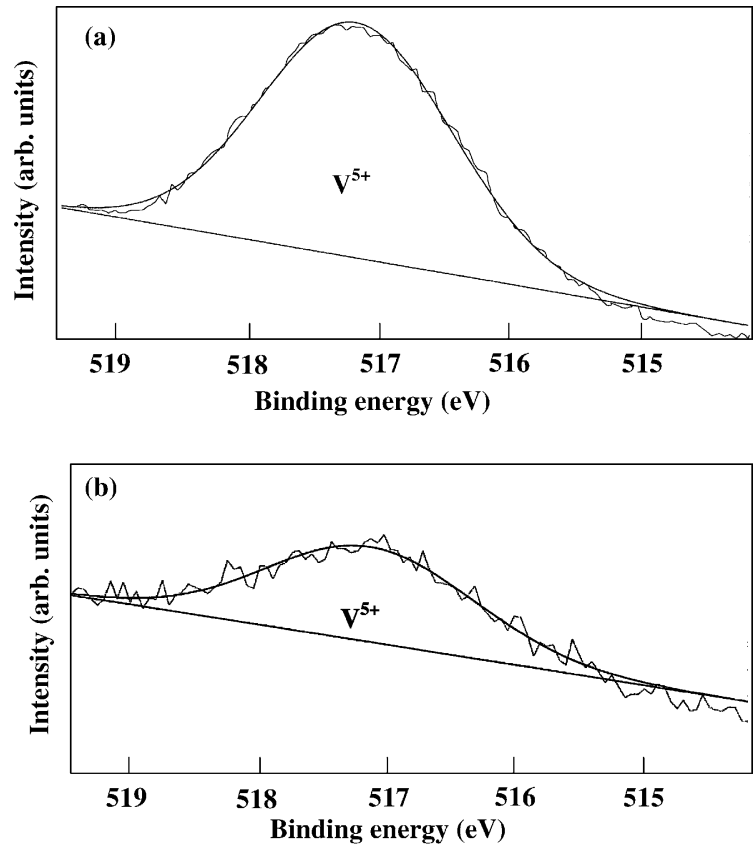

Fig. 7. The resulting fit (-) to the high-resolution $\mathrm{V} 2 \mathrm{p}_{3 / 2}$ spectra for (a) $x=0.098$ and (b) $x=0.048$ fractured glass samples.

one silicon atom instead of two $\mathrm{Si}$ atoms as they are in silica. These atoms $\left(\mathrm{Si}-\mathrm{O}^{-} \mathrm{Na}^{+}\right)$are termed 'non-bridging' oxygens, while those linking two silicon atoms ( $\mathrm{Si}-\mathrm{O}-\mathrm{Si})$ are termed 'bridging' oxygens. Since the chemical shift associated with the photoelectron transitions is intimately linked with the effective atomic charge on the oxygen atoms probed, an increase in the electron density on the relevant atom screens the core electrons and correspondingly decreases their measured binding energy. Therefore, the lower binding energy peak in the $\mathrm{O} 1 \mathrm{~s}$ spectrum is assigned to the NBO since the effective electronic charge on the oxygen atom in that environment is higher than that on the $\mathrm{BO}$ atom. Subsequently, each $\mathrm{O}$ 1s spectrum is fitted to a sum of Gaussian-Lorentzian peaks similar to those shown in Fig. 8(a) and (b) (corresponding to $x=0.075$ and 0.026 ) with the best fit found by varying the peak position, width and intensity of each of the two peaks. Table 4 shows the results of this fitting procedure as the ratio of the area under the non-bridging peak to the total area under the
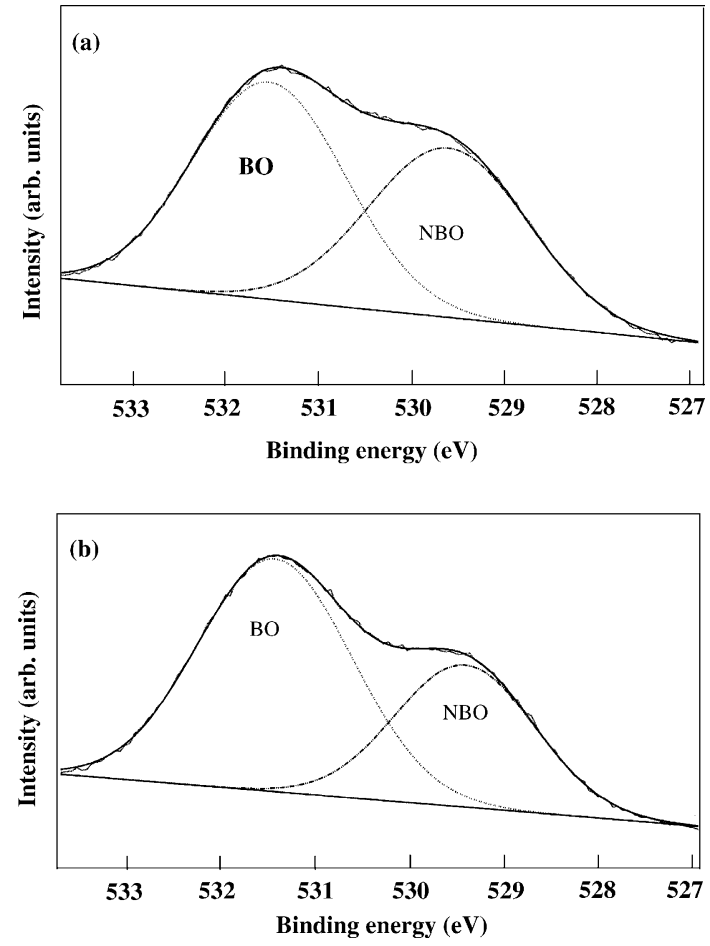

Fig. 8. The resulting fit (-) from the BO and NBO peaks (. - ·) to the high-resolution $\mathrm{O} 1 \mathrm{~s}$ spectra for (a) $x=0.075$ and (b) $x=0.026$ fractured glass samples.

two peaks, which is proportional to the ratio of NBO present, [NBO]/[TO]. Previous experimental studies [5] have found that the ratio [NBO]/[TO] for $0.30 \mathrm{Na}_{2} \mathrm{O}-0.70 \mathrm{SiO}_{2}$ to be 0.38 , in excellent agreement with our result. The percentage of nonbridging oxygen is found to increase with in-

Table 4

The BO-NBO energy separation and the measured relative area under the NBO peak to the total $\mathrm{O} 1$ s peak area as determined from the fitting of the $\mathrm{O}$ 1s spectra

\begin{tabular}{lllll}
\hline$x$ & $\begin{array}{l}\Delta E_{\mathrm{BO}-\mathrm{NBO}} \\
(\mathrm{eV})\end{array}$ & $\begin{array}{l}{[\mathrm{NBO}] /[\mathrm{TO}]} \\
\text { measured }\end{array}$ & $\begin{array}{l}{[\mathrm{NBO}] /[\mathrm{TO}]} \\
\text { calculated } \\
n=3\end{array}$ & $\begin{array}{l}{[\mathrm{NBO}] /[\mathrm{TO}]} \\
\text { calculated } \\
n=4\end{array}$ \\
\hline 0.000 & 1.90 & 0.380 & 0.367 & 0.367 \\
0.026 & 1.92 & 0.389 & 0.369 & 0.384 \\
0.048 & 1.96 & 0.418 & 0.383 & 0.409 \\
0.075 & 1.89 & 0.457 & 0.420 & 0.459 \\
0.098 & 1.82 & 0.493 & 0.439 & 0.488 \\
\hline
\end{tabular}

The accuracy in the measured ratio is $\pm 5 \%$. The calculated ratios of $[\mathrm{NBO}] /[\mathrm{TO}]$ are based on Eq. (1). 
creasing vanadium content in our glasses with no discernible change in peak position. Since $\mathrm{V}_{2} \mathrm{O}_{5}$ is essentially substituting for $\mathrm{SiO}_{2}$ in these glasses, the increasing contribution to the 'NBO' peak is due to $\mathrm{Si}-\mathrm{O}-\mathrm{V}, \mathrm{Na}-\mathrm{O}-\mathrm{V}$, and $\mathrm{V}=\mathrm{O}$ bonds replacing $\mathrm{Si}-\mathrm{O}-\mathrm{Si}$ bonds. The functional dependence of the $[\mathrm{NBO}] /[\mathrm{TO}]$ ratio must be of the form

$\frac{[\mathrm{NBO}]}{[\mathrm{TO}]}=\frac{2 z+n x}{z+2 y+5 x}=\frac{2 z+n x}{2-z+3 x}$,

where $n$ represents $\mathrm{V}-\mathrm{O}-\mathrm{V}$ and $\mathrm{V}=\mathrm{O}$ bonds and $z$, $y$, and $x$ are respectively the molar fractions of $\mathrm{Na}_{2} \mathrm{O}, \mathrm{SiO}_{2}$, and $\mathrm{V}_{2} \mathrm{O}_{5}$ as determined by ICP.

It is known that the addition of small amounts of $\mathrm{P}_{2} \mathrm{O}_{5}$ to alkali silicate glasses results in the removal of $\mathrm{Na}^{+}$from the silicate network to form alkali phosphate species such as orthophosphate, pyrophosphate, and metaphosphate depending on the $\mathrm{P}_{2} \mathrm{O}_{5}$ concentration $[34,35]$. The silicate network repolymerizes as a result of the $\mathrm{Na}^{+}$removal and the elimination of corresponding $\mathrm{Si}-\mathrm{O}-\mathrm{Na}$ bonds. If a similar process occurs with the introduction of $\mathrm{V}_{2} \mathrm{O}_{5}$ into the sodium silicate glasses, then $\mathrm{Na}^{+}$would be removed from the silicate network by the formation of alkali vanadates. Although $\mathrm{V}^{5+}$ may also exhibit a higher coordination than $\mathrm{P}^{5+}, \mathrm{V}_{2} \mathrm{O}_{5}$ can exist in several phosphate-like structural units such as pyrovanadate and metavanadate units when introduced into glasses [36]. Pyrovanadate $\left(\mathrm{V}_{2} \mathrm{O}_{7}^{4-}\right)$ would introduce $7 \mathrm{~V}-\mathrm{O}$ bonds of various types per $\mathrm{V}_{2} \mathrm{O}_{5}$ molecule but eliminate $4 \mathrm{Na}^{+}$atoms from the silicate network, or equivalently $4 \mathrm{NBO}$ atoms. This would result in a net gain of $3 \mathrm{NBO}$ atoms per $\mathrm{V}_{2} \mathrm{O}_{5}$ molecule, or an $n$ value of 3 in Eq. (1). Alternatively, metavanadate units $\left(\mathrm{V}_{m} \mathrm{O}_{3 m}^{m-}\right.$ with $\left.m=2\right)$ introduce $6 \mathrm{~V}-\mathrm{O}$ bonds per $\mathrm{V}_{2} \mathrm{O}_{5}$ molecule and eliminate $2 \mathrm{Na}^{+}$atoms, making $n$ equal to 4 . Ratios of [NBO]/[TO] calculated for $n=3$ and 4 are included in Table 4 and are compared to the experimental ratios in Fig. 9 as a function of $\mathrm{V}_{2} \mathrm{O}_{5}$ molar fraction. While the calculations of $[\mathrm{NBO}] /[\mathrm{TO}]$ for $n=3$ lie outside the experimental uncertainty of the measured ratios except for the $x=0.025$ glass sample, the calculated ratios for $n=4$ result in remarkably good agreement with the experimental results over the entire concentration range. This leads to the conclusion that metavanadate units of $\mathrm{NaVO}_{3}$ are

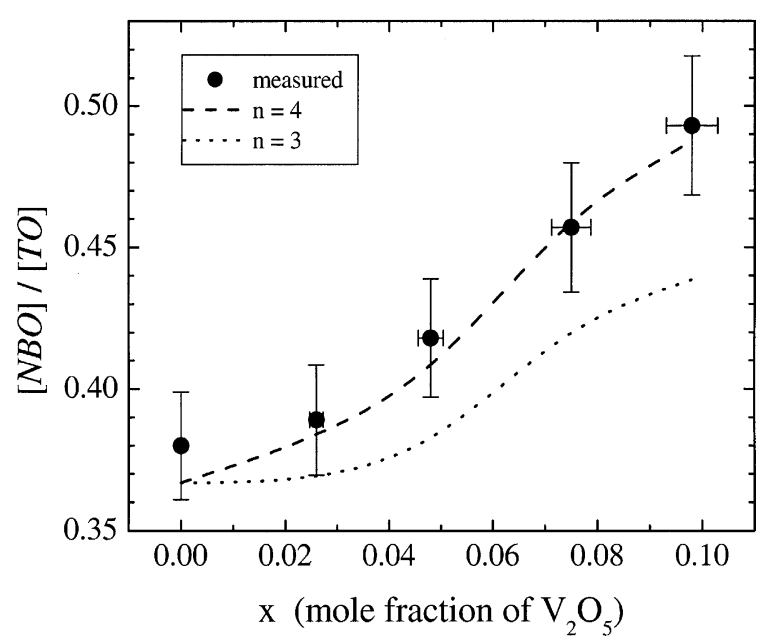

Fig. 9. Comparison of measured $[\mathrm{NBO}] /[\mathrm{TO}]$ ratios as afunction of $\mathrm{V}_{2} \mathrm{O}_{5}$ content to ratios calculated from Eq. (1) for different values of $n$.

most probably formed in this concentration range of $\mathrm{V}_{2} \mathrm{O}_{5}$ in sodium silicate glasses and that the silicate network is consequentially repolymerized. This analysis and resulting conclusion assumed that the contributions to the $\mathrm{O} 1 \mathrm{~s}$ peak from $\mathrm{V}-\mathrm{O}-$ $\mathrm{V}, \mathrm{V}-\mathrm{O}-\mathrm{Na}$ and $\mathrm{V}=\mathrm{O}$ occur within the binding energy range of $\mathrm{Si}-\mathrm{O}-\mathrm{Na}$ and therefore contribute to the NBO peak at $\sim 529.5 \mathrm{eV}$, which is a reasonable assumption since there is no experimental evidence for any additional peaks in the vicinity of this peak.

The best fit to the magnetic susceptibility data was found to consist of two contributions, a negative temperature-independent term and a simple Curie temperature-dependent term. The temperature-independent contribution can be understood in terms of the diamagnetism arising from the glass matrix as all the core ions are diamagnetic. However, $\mathrm{V}_{2} \mathrm{O}_{5}$ containing glasses must also take into account a temperature-independent paramagnetic contribution from $\mathrm{V}_{2} \mathrm{O}_{5}$ of the order of $10^{-4} \mathrm{emu} /$ mole Oe [37]. The result is that the constant background can be either positive or negative depending on the relative contribution of the two contributions. In the low $\mathrm{V}_{2} \mathrm{O}_{5}$ concentration sodium silicate glass system, the diamagnetism associated with $\mathrm{Na}_{2} \mathrm{O}$ and $\mathrm{SiO}_{2}$ wins out while the temperature independent paramagnetic $\mathrm{V}_{2} \mathrm{O}_{5}$ 
contribution dominates in the $\mathrm{B}_{2} \mathrm{O}_{3}-\mathrm{SrO}-\mathrm{V}_{2} \mathrm{O}_{5}$ glass system [38]. On the other hand, the Curie temperature-dependent behavior observed in these glasses must be associated with a fraction of the vanadium ions being in another oxidation state since $\mathrm{V}^{5+}$ ions are non-magnetic. The most probable, other oxidation state is $\mathrm{V}^{4+}$ which has a magnetic moment, $p_{\text {eff }}=1.73 \mu_{B}$. Taking this value in conjunction with measured Curie parameters and the $\mathrm{V}_{2} \mathrm{O}_{5}$ concentration determined by chemical analysis we find that magnetic $\mathrm{V}^{4+}$ ions are present at a level of $\sim 2 \%$ of the total $\mathrm{V}$ concentration for these glasses. This is well within the 5\% detection limit estimated for the XPS analysis where there is no discernible $\mathrm{V}^{4+}$ peak. Finally, the absence of a non-zero paramagnetic Curie temperature $\theta$ is not surprising since $\theta$ is proportional to the number of neighboring magnetic ions (negligible for these low $\mathrm{V}^{4+}$ concentrations) as well as the strength of the magnetic interaction.

\section{Conclusions}

The XPS technique has been used to investigate the effect of substituting various amounts of $\mathrm{V}_{2} \mathrm{O}_{5}$ for $\mathrm{SiO}_{2}$ in a $0.30 \mathrm{Na}_{2} \mathrm{O}-0.70 \mathrm{SiO}_{2}$ base glass. The XPS analysis of the V 2 p core level indicated that only $\mathrm{V}^{5+}$ ions were present in these glasses. The $\mathrm{O}$ $1 \mathrm{~s}$ spectra were fitted with a conventional twopeak fit and the number of NBO in each glass composition was found to correspond to contributions from $\mathrm{Si}-\mathrm{O}-\mathrm{Na}, \mathrm{V}-\mathrm{O}-\mathrm{V}, \mathrm{V}-\mathrm{O}-\mathrm{Na}$ and $\mathrm{V}=\mathrm{O}$ with vanadium being present predominantly in the form of $\mathrm{NaVO}_{3}$ units. Magnetic susceptibility results in the temperature range of $5-300 \mathrm{~K}$ were found to consist of a diamagnetic temperature-independent contribution arising from the glass matrix and a Curie temperature-dependent contribution associated with magnetic $\mathrm{V}^{4+}$ ions being present in concentration levels of $2 \%$ of the total $\mathrm{V}$ concentration, well below the detection limit of the XPS analysis of the V $2 p$ spectrum.

\section{Acknowledgements}

The support of the KFUPM Physics Department and Research Committee and of the $\mathrm{Na}$ - tional Science Foundation grant no. DGE9870720 is greatly acknowledged. We also wish to acknowledge Petru S. Fodor for his assistance with the magnetization measurements.

\section{References}

[1] G.D. McIntyre, M.G. Cook, Anal. Chem. 47 (1975) 2208.

[2] S. Huffner, G.K. Wertheim, Phys. Rev. B 8 (1973) 4857.

[3] C.G. Pantano, in: Experimental Techniques of Glass Science, American Ceramic Society, Westerville, OH, USA, p. 129.

[4] R. Gresch, W. Muller-Warmuth, J. Non-Cryst. Solids 4 (1979) 127.

[5] B.M.J. Smets, T.P.A. Lommen, J. Non-Cryst. Solids 46 (1981) 21.

[6] S. Mukhopadhyay, S.H. Garofalini, J. Non-Cryst. Solids 126 (1990) 202.

[7] P.I.K. Onorato, M.N. Alexander, C. Struck, G.W. Tasker, D.R. Uhlmann, J. Am. Ceram. Soc. 68 (1985) 148.

[8] B.M.J. Smets, D.M. Krol, Phys. Chem. Glasses 25 (1984) 113.

[9] C.H. Hsieh, H. Jain, A.C. Miller, E.I. Kamitsos, J. NonCryst. Solids 168 (1994) 247.

[10] R.K. Brow, R.J. Kirkpatrick, G.L. Turner, J. Am. Ceram. Soc. 73 (1990) 2293.

[11] Z. Hussain, M.A. Salim, M.A. Khan, E.E. Khawaja, J. Non-Cryst. Solids 110 (1989) 127.

[12] A. Mekki, D. Holland, C.F. McConville, M. Salim, J. Non-Cryst. Solids 208 (1996) 267.

[13] A. Mekki, D. Holland, C.F. McConville, J. Non-Cryst. Solids 215 (1997) 271.

[14] R.K. Brow, C.M. Arens, X. Yu, E. Day, Phys. Chem. Glasses 35 (1994) 132.

[15] A. Mekki, D. Holland, Kh.A. Ziq, C.F. McConville, Phy. Chem. Glasses 39 (1998) 45.

[16] G.D. Khattak, E.E. Khawaja, L.E. Wenger, M.A. Salim, A.B. Hallak, J. Non-Cryst. Solids 194 (1996) 1.

[17] G.D. Khattak, M.A. Salim, L.E. Wenger, A.H. Gilani, J. Non-Cryst. Solids 244 (1999) 128.

[18] M.A. Salim, G.D. Khattak, P.S. Fodor, L.E. Wenger, J. Non-Cryst. Solids 289 (2001) 185.

[19] J.D. Mackenzie, in: Modern Aspects in the Vitreous State, 3, Butterworth, London, 1964.

[20] N.F. Mott, J. Non-Cryst. Solids 1 (1968) 1.

[21] D. Adler, Amorphous Semiconductors, CRC, Cleveland, $\mathrm{OH}, 1971$.

[22] I.G. Austine, E.J. Garbett, in: P.G. LeComber, J. Mart (Eds.), Electronic and Structural Properties of Amorphous Semiconductors, Academic Press, London, 1973.

[23] M. Sayer, A. Mansingh, Phys. Rev. B 6 (1972) 4629.

[24] G.S. Linsley, A.E. Owen, F.M. Hyayatee, J. Non-Cryst. Solids 4 (1970) 208.

[25] G.W. Anderson, F.U. Luehrs, J. Appl. Phys. 39 (1968) 1634. 
[26] L.D. Bogomolova, J. Non-Cryst. Solids 30 (1979) 379.

[27] L.D. Bogomolova, M.P. Glassova, J. Non-Cryst. Solids 37 (1980) 423.

[28] L.D. Bogomolova, M.P. Glassova, O.E. Dubatovko, S.I. Reiman, S.N. Spasibkina, J. Non-Cryst. Solids 58 (1983) 71.

[29] B.S. Bae, M.C. Weinberg, J. Am. Ceram. Soc. 74 (1991) 3039 .

[30] A. Mekki, PhD thesis, University of Warwick, UK, 1997.

[31] A. Proctor, P.M.A. Sherwood, Anal. Chem. 52 (1980) 2315.

[32] E.Z. Kurmaev et al., J. Phys.: Condens. Matter 10 (1998) 4081.
[33] M. Demeter, M. Neumann, W. Reichelt, Surf. Sci. 454-456 (2000) 41.

[34] R. Dupree, D. Holland, M.G. Mortuza, Phys. Chem. Glasses 29 (1988) 18.

[35] R. Dupree, D. Holland, M.G. Mortuza, J.A. Collins, M.W.G. Lockyer, J. Non-Cryst. Solids 106 (1988) 403.

[36] S. Hayakawa, T. Yoko, S. Sakka, J. Non-Cryst. Solids 183 (1995) 73.

[37] Y. Kawamoto et al., JNCS 38\&39 (1980) 301.

[38] M. Chinkhota, P.S. Fodor, G.D. Khattak, L.E. Wenger, J. Magn. Magn. Mater. 91 (2002) 8269. 